\title{
The Role of Vitamin D Deficiency in Children With Recurrent Wheezing-Clinical Significance
}

\author{
Gavriela Feketea ${ }^{1,2 * t}$, Corina I. Bocsan ${ }^{3 t}$, Luminita Aurelia Stanciu ${ }^{4}$, Anca Dana Buzoianu ${ }^{3}$ \\ and Mihnea Tudor Zdrenghea ${ }^{1,5}$ \\ 'Department of Hematology, "Iuliu Hatieganu" University of Medicine and Pharmacy, Cluj-Napoca, Romania, ${ }^{2}$ Department of \\ Pediatrics, Pediatric Allergy Outpatient Clinic, "Karamandaneio" Children Hospital, Patras, Greece, ${ }^{3}$ Department of \\ Pharmacology, Toxicology and Clinical Pharmacology, "Iuliu Hatieganu" University of Medicine and Pharmacy, Cluj-Napoca, \\ Romania, ${ }^{4}$ Airways Disease Infection Section, National Heart and Lung Institute, Imperial College London, London, \\ United Kingdom, ${ }^{5}$ Department of Hematology, Ion Chiricuta Oncology Institute, Cluj-Napoca, Romania
}

\section{OPEN ACCESS}

Edited by:

Kostas N. Prittis,

National and Kapodistrian University

of Athens, Greece

Reviewed by:

Jung Yeon Shim,

Sungkyunkwan University,

South Korea

Mioara D. Manole,

University of Pittsburgh, United States

*Correspondence:

Gavriela Feketea

gabychri@otenet.gr

Corina I. Bocsan

bocsan.corina@umfcluj.ro

†These authors have contributed equally to this work

Specialty section:

This article was submitted to Pediatric Pulmonology, a section of the journal

Frontiers in Pediatrics

Received: 06 December 2019

Accepted: 26 May 2020

Published: 30 June 2020

Citation:

Feketea G, Bocsan Cl, Stanciu LA, Buzoianu AD and Zdrenghea MT

(2020) The Role of Vitamin D

Deficiency in Children With Recurrent

Wheezing-Clinical Significance.

Front. Pediatr. 8:344.

doi: 10.3389/fped.2020.00344
Recurrent wheezing (RW) in infancy is one of the most frequent reasons for parents to consult health care providers and creates a significant global burden. Clinical course of RW is difficult to predict, also which infants will progress to asthma, since no valid biomarkers have been established. Identification of those infants with RW who are at risk of further recurrences and/or severe acute respiratory tract infection (ARTI) could help pediatricians to improve their therapeutic decisions. Increasing research interest is focused on the extra-skeletal actions of vitamin D (VD) and the clinical impact of VD insufficiency/deficiency. As VD deficiency could be a risk factor for causing RW in children, measurement of their serum level of 25-hydroxycholecalciferol [25(OH)D] is recommended. In the case of deficiency, VD administration is recommended in age-appropriate doses for at least 6 weeks, until achievement of normal blood 25(OH)D level, followed by supplementation as long as exposure to sun is inadequate. Higher doses of VD given in an attempt to prevent asthma development appear to be of no additional benefit. In children with severe ARTI, VD level is recommended to be assess.

Keywords: vitamin D, 25(OH)D, vitamin D receptor (VDR), recurrent wheezing, asthma, respiratory allergies

\section{KEY POINTS-QUESTIONS}

Could vitamin D status be a biomarker for risk of ARTI in children with recurrent wheezing?

Does vitamin D supplementation affect the incidence and clinical course of ARTI?

Does vitamin D supplementation modify development of respiratory allergies (asthma)?

\section{MEANING}

- Children with recurrent wheezing may be vitamin D deficient, and their serum level of $25(\mathrm{OH}) \mathrm{D}$ would be useful for identifying those children who would benefit from vitamin D supplementation.

- Vitamin D supplementation may reduce the risk of respiratory infection and asthma exacerbation in some clinical contexts. In the case of deficiency, vitamin $\mathrm{D}$ should be administered in daily dose depending on age, for at least 6 weeks, until achievement of a normal serum $25(\mathrm{OH}) \mathrm{D}$ level, followed by supplementation when sun exposure is inadequate.

- In deficient children, higher doses of vitamin D appear to provide no extra benefit in modifying the clinical course of ARTIs or preventing asthma. 


\section{INTRODUCTION}

Vitamin D (VD) research has been focused increasingly on its extra-skeletal actions and its possible role in immune system modulation, and on the clinical impact of VD insufficiency. Viral lower respiratory tract infection, acute viral bronchitis, acute bronchiolitis, viral pneumonia, viral wheeze, recurrent/transient/multi-trigger wheezing, and viral induced exacerbation of asthma are only a few of the vast range of terms used as diagnostic labels for respiratory illnesses cause by respiratory viruses in infancy and early childhood (1). Recurrent wheezing (RW) in infancy is one of the most frequent reasons for parents to consult health care providers and constitutes a huge global burden. This review analyzes the current evidence for the relationship between VD status and RW in infancy and childhood, including potential progress to asthma, and the effects of VD supplementation.

\section{RECURRENT WHEEZING}

Many different conditions can produce "wheezing," which is a musical sound caused by the passage of air through narrow respiratory tract airways, but this airway narrowing is caused most often by acute respiratory tract infection (ARTI) (2). RW in children aged $\leq 5$ years is a heterogeneous condition, typically associated with recurrent upper respiratory tract infections (URTIs). As each patient may have 6-8 episodes of URTI per year, the question of whether a wheezing episode is an initial or a recurrent clinical event constitutes a challenge to the clinician, but RW is generally defined as 2 or more episodes of reported wheezing since birth. Wheezing phenotypes proposed by the European Respiratory Society (ERS) Task Force in 2008 differ, based on the criteria used for classification: episodic viral or multiple-trigger wheeze, according to symptombased classification; transient, persistent and late-onset wheeze, according to time trend-based classification (3). Theoretically, this approach enables individual therapeutic decisions to be made based on the temporal pattern of symptoms (4). In clinical practice, so many infants and young children present wheezing with viral infections that early allocation to one of these phenotypes is unrealistic (5). Identification of those infants with RW at risk for future recurrence and/or severe evolution could help pediatricians to optimize their therapeutic decisions.

\section{VITAMIN D}

\section{Sources and Metabolism}

VD in the human organism comes from exposure to sunlight and from food and supplements. Ultraviolet B radiation converts 7-dehydrocholesterol to previtamin $\mathrm{D}_{3}$ and subsequently to vitamin $D_{3}$ (6). Foods provide vitamins $D_{2}$ and $D_{3}$, supplements prescribed for treatment in the US contain $\mathrm{D}_{2}$, while those for prevention, and all European supplements, contain $\mathrm{D}_{3}$ (7). VD from all sources is metabolized in the liver to 25-hydroxyvitamin $\mathrm{D}[25(\mathrm{OH}) \mathrm{D}]$ which is further transformed in the kidneys by the enzyme $1 \alpha$-hydroxylase $[1 \alpha(\mathrm{OH})$ ase, CYP27B1] to its active form, 1,25-dihydroxyvitamin $\mathrm{D}\left[1,25(\mathrm{OH})_{2} \mathrm{D}\right](6)$. In addition, synthesis of the biologically active metabolite $1,25(\mathrm{OH})_{2} \mathrm{D}$ takes place intracellularly (8). The effects of $1,25(\mathrm{OH})_{2} \mathrm{D}$ are mediated through specific high-affinity vitamin $\mathrm{D}$ receptor (VDR) via upregulating or downregulating target genes (9).

\section{Local Immunomodulatory and Antiviral Activity of Vitamin D}

During a lower respiratory infection, various factors, virusdependent and host-dependent, regulate the development and severity of infections. It has been suggested that host reactions to viral infection, rather than the direct viral injury, are responsible for the clinical and pathological manifestations (10) and contribute to the development of RW after repeated ARTI. Different respiratory viruses will produce an immune host response mediated by both $\mathrm{T}$ and $\mathrm{B}$ cells.

In addition to well-researched functions in calcium homeostasis, VD and VDR modulate both the innate and the adaptive immune response, and play a key role in the balance between T-helper 1 and T-helper 2 (Th1-Th2) cytokines $(11,12)$.

In vitro studies suggest that $\mathrm{VD}$ induces a shift in the balance between Th1-type and Th2-type cytokines toward Th2 dominance (2). It has been shown that VD decreases the proinflammatory type 1 cytokines: IL-12, interferon-gamma (IFN- $\gamma)$, IL-6, IL-8, tumor necrosis factor alpha (TNF $\alpha$ ) and IL-17 and increase anti-inflammatory IL-10 and Th2 cytokines: IL-4 and IL-5 (13-15). A few human studies demonstrated the shift toward Th2, while others do not confirm these results. The relationship between serum VD levels and asthma remains controversial, and a U-shaped association has been suggested, with both VD deficiency and high levels of VD leading to a risk of asthma and allergy (16).

VD modulates $B$ cell activities, influencing production of immunoglobulin E (IgE), and decreasing cell proliferation and differentiation but increasing apoptosis (15). In a British birth cohort, at the age of 45 years, IgE concentrations were higher in both subjects with $\mathrm{VD}<25 \mathrm{nmol} / \mathrm{l}$ and those with VD $>135 \mathrm{nmol} / \mathrm{l}$, suggesting that both low and high VD levels are associated with elevated IgE levels, confirming the U-shaped relationship (17). A review of in vitro experiments investigating the immunomodulatory activity of VD revealed no influence on replication or clearance of respiratory viruses in human respiratory epithelial cells (15).

The respiratory viruses, rhinovirus (RV) and respiratory syncytial virus (RSV) are reported to downregulate VDR mRNA expression in primary bronchial epithelial cells (PBECs). RV replication and its capacity to infect epithelial cells were found reduced in VD treated PBECs, suggesting that this might contribute to the antiviral activity of vitamin $\mathrm{D}$ (18).

In vitro and animal studies have shown an inhibitory effect of VD on airway smooth muscle cells, suggesting implication of VD in airway remodeling, which may be a primary event in asthma pathogenesis $(19,20)$.

Despite lack of solid documentation, it is generally accepted that VD deficiency has effects not only on calcium homeostasis and bone health but also on non-skeletal diseases (21), as shown in Figure 1 (22). 


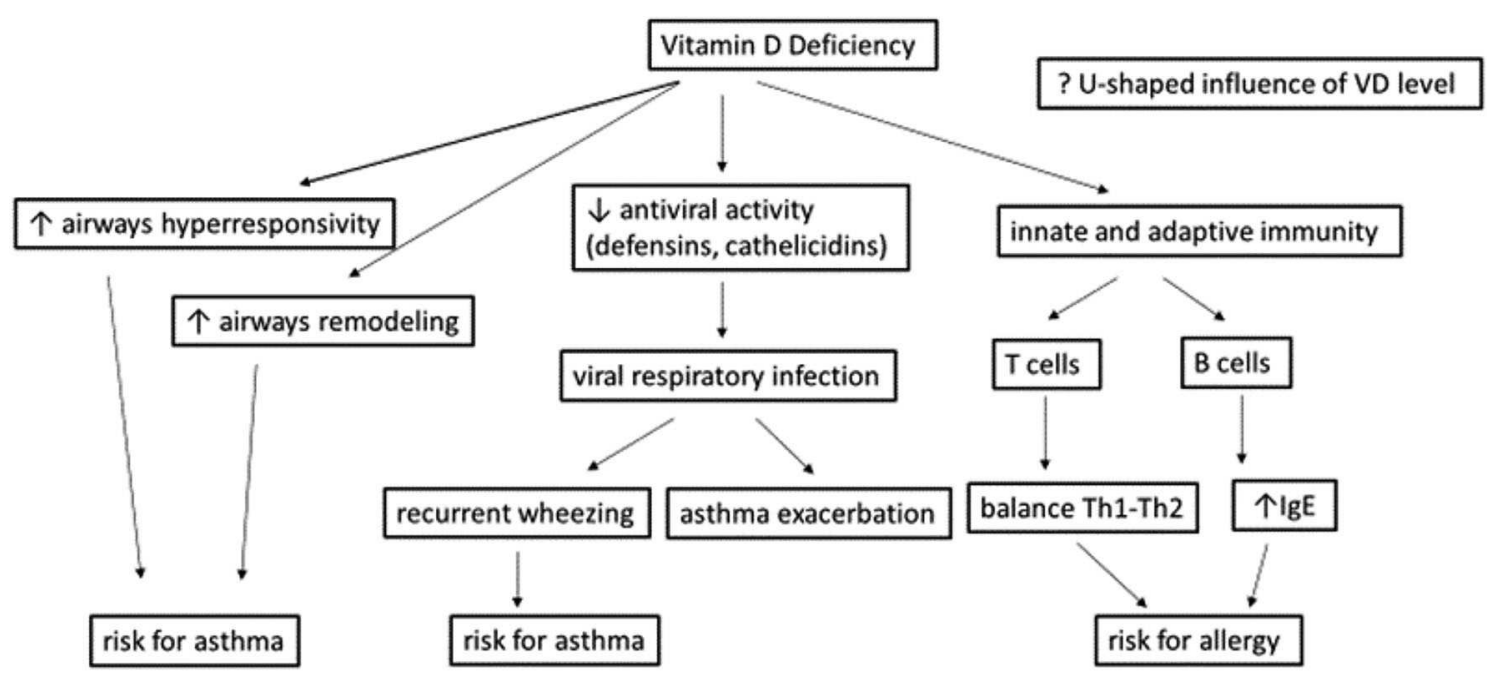

FIGURE 1 | Potential effects of vitamins D deficiency during a viral respiratory infection [adapted from Mirzakhani et al. (22)].

\section{Vitamin D Requirements in Childhood}

Needs for VD intake depend on latitude, season, ethnicity, age, body weight, health status, dress habits and use of sunscreen creams. Many experts suggest that both children and adults should take $\geq 800-1,000 \mathrm{IU}$ vitamin $\mathrm{D} /$ day from dietary and supplemental sources when exposure to sunlight is unable to provide it (23). Sacheck and colleagues showed that children at risk for vitamin $\mathrm{D}$ deficiency achieved a higher mean $25(\mathrm{OH}) \mathrm{D}$ serum level after 3 months daily supplementation with 2,000 IU/day than with 600 and 1,000 IU/day, doses closer to the current recommended daily allowance (24). The Endocrine Society Practice Guidelines Committee (Table 1) and the European Academy of Pediatrics (EAP) recommend for prevention in infants ( $0-1$ year) and children ( $1-18$ years) at risk of vitamin D deficiency, 400-1,000 IU/day, and 600-1,000 IU/day, respectively (25).

For treatment of deficiency, 2,000 IU/day for at least 6 weeks, to achieve a serum $25(\mathrm{OH}) \mathrm{D}$ level $>30 \mathrm{ng} / \mathrm{ml}$ has been suggested, followed by doses as for prevention (26). Administration of VD to patients with low baseline $25(\mathrm{OH}) \mathrm{D}$ levels should be in doses sufficient to achieve normal levels (i.e., treatment of deficiency not supplementation). Studies to date have produced conflicting findings of relative efficacy but both vitamin $\mathrm{D}_{2}$ and $\mathrm{D}_{3}$ are recommended (26).

Few pediatricians, however, apply these guidelines in practice. DelGiudice and colleagues report that although most primary care providers are aware that vitamin D deficiency is common, fewer than half currently recommend 600-1,000 IU supplementation for their pediatric patients (27).

\section{Vitamin D Status: Deficiency-Insufficiency Definitions}

Serum or plasma level of total 25(OH)D is currently used as the indicator of VD status (28). Almost all professional associations define VD status as sufficient when the level of
$25(\mathrm{OH}) \mathrm{D}$ is at least $30 \mathrm{ng} / \mathrm{mL}$, insufficient at $21-29 \mathrm{ng} / \mathrm{mL}$ and deficient at $<20 \mathrm{ng} / \mathrm{mL}$ (7). The European Society for Pediatric Gastrenterology, Hepatology and Nutrition (ESPGAHN) characterizes as sufficient serum $25(\mathrm{OH}) \mathrm{D}$ concentrations $>50 \mathrm{nmol} / \mathrm{L}(20 \mathrm{ng} / \mathrm{ml})$, and $<25 \mathrm{nmol} / \mathrm{L}(10 \mathrm{ng} / \mathrm{ml})$ as severe deficiency (29). To convert 25(OH)D from $\mathrm{ng} / \mathrm{mL}$ to $\mathrm{nmol} / \mathrm{L}$, multiply by 2.496 (28).

Current recommendations for VD screening concern only groups of children at risk for VD deficiency. Obesity, pigmented skin, inadequate diet intake, indoor lifestyle, lack of sunlight exposure (beyond a latitude of $35^{\circ}$ ), use of sun screen, liver disease, drugs (rifampicin, glucocorticoids, anticonvulsants) are all risk factors for VD deficiency and insufficiency in children (30). Following improved understanding of VD involvement in host reactions against infection and within the immune system, both innate and adaptive, the relevant guidelines have begun to include groups with recurrent RTI and asthma (31).

\section{VITAMIN D STATUS AND RECURRENT WHEEZING/VIRAL RESPIRATORY INFECTION}

Epidemiological and observational studies have demonstrated a clear association between VD deficiency and viral respiratory infections in certain contexts, while interventional studies on VD supplementation and/or VD status have had mixed findings.

\section{Relationship Between Vitamin D Deficiency and Wheezing and/or Viral Respiratory Tract Infections}

The most common viruses responsible for acute respiratory infections in infants and children are the influenza virus, RVs, RSV and metapneumovirus. Only few VD studies have identified the exact type of viral infection, but found no association of VD 
TABLE 1 | Vitamin D requirements according to age; doses recommended by the Endocrine Society Practice Guidelines Committee, for prevention and treatment of vitamin D deficiency, and upper limits for administration without risk of adverse events (26).

\begin{tabular}{|c|c|c|c|c|c|}
\hline $\begin{array}{l}\text { Recommended daily } \\
\text { dose (IU) of vitamin D }\end{array}$ & 0-6 months & 6-12 months & $1-3$ years & 4-8 years & 8-18 years \\
\hline Prevention* & & & & $600-1,000$ & \\
\hline $\begin{array}{l}\text { Treatment of } \\
\text { deficiency }^{\star \star}\end{array}$ & & & & 2,000 & \\
\hline Tolerated upper limit & 2,000 & 2,000 & 4,000 & 4,000 & 4,000 \\
\hline
\end{tabular}

25(OH)D $=25$ hydroxy vitamin $D$.

*In patients at risk for vitamin $D$ deficiency.

${ }^{\star \star}$ For at least 6 weeks, to achieve a blood level of 25(OH)D > $30 \mathrm{ng} / \mathrm{ml}$.

levels with the presence of a certain virus, except in patients with positive RSV, RV or coinfections (32).

Eroglu and colleagues recently showed that $25(\mathrm{OH}) \mathrm{D}_{3}$ levels were significantly lower in children with RW than in a healthy control group, and had no relationship with hospitalization, oxygen, or steroid treatment (33). In an earlier study, a significantly lower mean 25(OH)D level was observed in patients with RW than in a healthy control group, and the level was negatively correlated with the duration of wheezing, number of wheezing episodes and systemic glucocorticoid need (34). Conversely, Pecanha and colleagues showed no association between $25(\mathrm{OH}) \mathrm{D}$ concentration and exacerbations, as assessed on the basis of hospitalizations, emergency department (ED) visits, and oral corticosteroid use in children with RW, but observed an association with onset of wheezing before the age of 1 year (35).

McNally and colleagues investigated 105 children aged $<5$ years with ARTI (bronchiolitis and pneumonia) requiring hospitalization, and 92 control children. Mean 25(OH)D level were not significantly different in the control and ARTI groups but were significantly lower in the 16 children with ARTI requiring PICU admission (15\%) than in both the control subjects and children in the general pediatric ward. The authors concluded that deficient VD status may influence the severity of ARTI, but not the risk of hospitalization (36). Similarly, in a 17-center prospective cohort study of infants hospitalized with bronchiolitis, those with total $25(\mathrm{OH}) \mathrm{D}<20 \mathrm{ng} / \mathrm{ml}$ had an increased risk of intensive care and longer hospital lengthof-stay (37). In a study comparing 64 infants hospitalized in a general pediatric ward for ARTI and 65 control subjects, all aged 1 month -2 years, mean $25(\mathrm{OH}) \mathrm{D}$ and prevalence of $\mathrm{VD}$ deficiency/insufficiency were similar in the two groups, and not associated with risk of hospitalization for ARTI (38). A review of 12 studies showed that the children with LRTI had significantly lower mean VD levels than the control subjects, and demonstrated a correlation between VD levels and the incidence and severity of LRTI (39).

Evidence generated from recent meta-analyses revealed that increased prenatal exposure to $25(\mathrm{OH}) \mathrm{D}$ (measured as cord blood or maternal venous blood) was inversely associated with risk for wheeze and/or RTI, in the offspring, while for asthma the evidence was mixed (40-42). The inverse association for wheeze was more pronounced and statistically significant in the studies that measured $25(\mathrm{OH}) \mathrm{D}$ levels in cord blood (43).

\section{Role of Vitamin D Supplementation and Wheezing (Antenatal-Postnatal, Prevention -Treatment)}

Almost all interventional studies support the value of VD supplementation in pregnancy in reducing the prevalence of RW in infants. The findings of efficacy studies of VD supplementation in infancy are contradictory regarding viral respiratory infection.

\section{Antenatal Vitamin D Supplementation}

The VD Antenatal Asthma Reduction Trial (VDAART) was a trial of prenatal VD supplementation, in which 440 women were randomized to receive $4,000 \mathrm{IU} /$ day $\mathrm{VD}$, and 436 women only $400 \mathrm{IU}$. The incidence of asthma and RW in their children at the age of 3 years was lower by $6.1 \%$ in the group with the higher intake, but this did difference was not statistically significant (28). Prenatal VD supplementation did not affect the development of asthma and RW at the age of 6 years (44). These results suggest that antenatal supplementation alone does not provide adequate protection, and postnatal supplementation is needed. In a meta-analysis of data from 16 birth cohorts, Feng showed that increased antenatal exposure to $25(\mathrm{OH}) \mathrm{D}$ is inversely related to the risk of asthma and wheeze in the offspring, but not respiratory tract infections (43).

\section{Postnatal Vitamin D Supplementation}

In 703 healthy children aged 1-5 years, administration of 2,000 IU, compared with $400 \mathrm{IU}$, of VD for a minimum of 4 months between September and May did not reduce the prevalence of upper ARTI during the winter (45). A secondary analysis of this multisite RCT assessing whether wintertime high-dose VD supplementation reduces URTI symptom severity and frequency of ED visits compared with low-dose found no differences; no data about the baseline VD levels are available (46). Even in children with a baseline serum 25(OH)D level $<30 \mathrm{ng} / \mathrm{mL}$, the incidence per person-year was no different (47). Laboratory confirmed ARTI was slightly more frequent 
in the high-dose than the standard dose group, and the authors concluded that VD in doses $>400$ IU/day may not be indicated for preventing winter ARTIs in children (45). A 2017 meta-analysis of data from randomized controlled trials (RCTs) demonstrated that VD supplementation reduced the risk of at least one ARTI. Daily or weekly supplementation without additional bolus doses protected against ARTI, with the strongest effect in those with the lowest baseline $25(\mathrm{OH}) \mathrm{D}$ (48). Among 277 black infants born premature, 147 were consuming $200 \mathrm{IU} /$ day from diet and 150 additional 400 IU/day from medical supplementation, which reduce the risk of RW by 12 months (49). Recently, 650 healthy children and adolescents were randomly assigned to taking 14,000 UI vitamin D weekly and 650 to taking placebo, for 8 months. No significant difference was observed between the vitamin D and placebo groups for influenza, but non-influenza respiratory viral infections were significantly reduced in the vitamin D group. When considering all respiratory virus infections, including influenza, the effect of vitamin $\mathrm{D}$ in reducing infection was also significant (50). In a recent prospective birth cohort study from China, infants receiving 400-600 IU of vitamin $\mathrm{D}$ from birth were divided into 4 groups, according to the average frequency of supplementation $(0,1-2,3-4$, and 5-7 days/week). Inverse trends were observed between supplementation and risk of ARTI, LRTI, and ARTI-related hospitalization (51).

Overall, the RCTs to date, while not uniform in their results, provide indications that VD supplementation, taken daily or weekly without bolus, can lower the risk of severe ARTI in children with low baseline 25(OH)D (2).

There is a lack of evidence on administration of VD to infants during an ARTI, and the optimal dose and timing. A recent Cochrane review evaluated 4 studies involving 780 children with pneumonia and 3 studies including 749 children with severe or very severe pneumonia, all aged $<5$ years. Various doses and methods of administration of VD were used, but, because of low and very low-quality evidence, the reviewers remained uncertain as to whether oral vitamin $\mathrm{D}$ as an a adjunct to treatment of acute pneumonia in children $<5$ years has an effect on outcome (52).

\section{Vitamin D and Primary Prevention of Respiratory Allergies}

RW caused by respiratory viral and/or bacterial infections in infancy and early childhood often persists after the age of 7 years, and asthma becomes established. Interventional studies in pregnancy tend to support the value of maternal VD supplementation in reducing the prevalence of childhood asthma, in contrast to studies on supplementation in infancy, which show contradictory results. Once initiated, asthma appears to have an association with VD status. A systematic review identified 23 manuscripts (two casecontrol, 12 cohort and nine cross-sectional studies) and found that higher serum levels of VD are associated with a reduced risk of asthma exacerbations, but little evidence to suggest an association with asthma incidence, prevalence or severity (53).

\section{VITAMIN D AS BIOMARKER}

In local inflammation produced by respiratory viruses, the activity of enzymes responsible for synthesis $[1 \alpha(\mathrm{OH})$ ase $]$ and degradation [24(OH)ase] of the active vitamin $\mathrm{D}$ metabolite $1,25(\mathrm{OH}) \mathrm{D}_{2}$ is dysregulated. In order to exercise their antiviral role, local macrophage and other immune cells release antiviral proteins (cathelicidin, defensis and innate interferons) (9). It is possible that in more severe viral infections the higher release of antiviral proteins decreases the activity of inactivating $24(\mathrm{OH})$ ase and increases the activity of $1 \alpha(\mathrm{OH})$ ase. Consequently, the concentration of $1,25(\mathrm{OH}) \mathrm{D}_{2}$ is increased in extra-renal tissues, to the detriment of serum $25(\mathrm{OH}) \mathrm{D}$ from which it is synthesized. A severe viral infection during periods when VD intake and exposure to sunlight are reduced may thus result in low serum $25(\mathrm{OH}) \mathrm{D}$. It has yet to be shown in the real-life situation whether or not VD level could be used as a biomarker for the severity of ARTIs. Current evidence suggests that VD supplementation may reduce the risk of severe ARTI in some clinical situations, depending on both host and virus characteristics. The changes at the molecular level may differ, depending on type of virus. Urashima and colleagues, studying the effect of 1,200 IU/day of vitamin D supplementation vs. placebo on the incidence of seasonal influenza $\mathrm{A}$ and $\mathrm{B}$ among children aged 6-15 years, showed reduced incidence of influenza A but not of influenza $B$ infection (54). Production of active metabolite VD resulted in initial increase in $25(\mathrm{OH}) \mathrm{D}$ in blood, and consequently in the respiratory tract; sufficient $\mathrm{VD}$ increases the antiviral activity of respiratory epithelial cells (18).

As VD supplementation is not followed by reduction in RW or asthma prevalence, although VD deficiency is associated with both conditions, an inverse causal relationship could be hypothesized. In both asthma and in RW, local $25(\mathrm{OH}) \mathrm{D}$ is needed to produce $1,2(\mathrm{OH})_{2} \mathrm{D}$. Recent studies showed that many innate immune cells can synthesize $1,2(\mathrm{OH})_{2} \mathrm{D}$ from $25(\mathrm{OH}) \mathrm{D}$ (9). Whether low VD during ARTI is a co-factor in their appearance, or a result of local transformation to the active form to combat infection is unclear. Sophisticated determinations to conclude which children respond positively to intervention are not feasible in primary care, but it may be useful to measure VD during a new ARTI, and to correct deficiency, in children with RW.

\section{CONCLUSIONS}

New biomarkers are needed for early identification of those children with RW who are at increased risk of severe ARTI and require intensive treatment and close follow-up. VD status appears to be a suitable candidate in certain populations. As VD deficiency could be a risk factor for causing RW in children, measurement of their serum level of $25(\mathrm{OH}) \mathrm{D}$ is recommended. In the case of deficiency, VD should be administrated in doses 
according to age for at least 6 weeks, until achievement of normal blood 25(OH)D level, followed by supplementation when exposure to sunlight is inadequate. Higher doses of VD in this group in an effort to influence the clinical course and prevent asthma appear to be of no additional benefit. In a new era of personalized medicine, decisions based on appropriate treatment for different wheezing phenotypes may be possible.

\section{FURTHER RESEARCH}

Further research is needed in this area, including well-designed RCT or longitudinal study, to confirm VD role in severe infection and analyze the risk factor in recurrent wheezing.

\section{REFERENCES}

1. Douros K, Everard ML. Time to say goodbye to bronchiolitis, viral wheeze, reactive airways disease, wheeze bronchitis and all that. Front. Pediatr. (2020) 8:218. doi: 10.3389/fped.2020.00218

2. Camargo CA. Chapter 112 - vitamin D, acute respiratory infection, and asthma/chronic obstructive pulmonary disease. In: Feldman D, editor. Vitamin D (Fourth Edition) London: Academic Press (2018) p. 1095-120.

3. Brand PLP, Baraldi E, Bisgaard H, Boner AL, Castro-Rodriguez JA, Custovic A, et al. Definition, assessment and treatment of wheezing disorders in preschool children: an evidence-based approach. Eur Resp J. (2008) 32:1096110. doi: 10.1183/09031936.00002108

4. Report GM. Global Strategy Forasthma Management and Prevention Updated 2020. (2018) Available online at: https://ginasthma.org/wp-content/uploads/ 2020/06/GINA-2020-report_20_06_04-1-wms.pdf. (accessed May 14, 2020).

5. Brand PL, Caudri D, Eber E, Gaillard EA, Garcia-Marcos L, Hedlin G, et al. Classification and pharmacological treatment of preschool wheezing: changes since 2008. Eur Respir J. (2014) 43:1172-7. doi: 10.1183/09031936.00199913

6. Holick MF. Vitamin D deficiency. N Engl J Med. (2007) 357:26681. doi: 10.1056/NEJMra070553

7. Holick MF. The vitamin D deficiency pandemic: approaches for diagnosis, treatment and prevention. Rev Endocr Metab Disord. (2017) 18:15365. doi: 10.1007/s11154-017-9424-1

8. Jolliffe DA, Greiller CL, Mein CA, Hoti M, Bakhsoliani E, Telcian AG, et al. Vitamin D receptor genotype influences risk of upper respiratory infection. $\mathrm{Br}$ J Nutr. (2018) 120:891-900. doi: 10.1017/S000711451800209X

9. Zdrenghea MT, Makrinioti H, Bagacean C, Bush A, Johnston SL, Stanciu LA. Vitamin D modulation of innate immune responses to respiratory viral infections. Rev Med Virol. (2017) 27:e1909. doi: 10.1002/rmv.1909

10. Newton AH, Cardani A, Braciale TJ. The host immune response in respiratory virus infection: balancing virus clearance and immunopathology. Semin Immunopathol. (2016) 38:471-82. doi: 10.1007/s00281-016-0558-0

11. Bozzetto S, Carraro S, Giordano G, Boner A, Baraldi E. Asthma, allergy and respiratory infections: the vitamin D hypothesis. Allergy. (2012) 67:107. doi: 10.1111/j.1398-9995.2011.02711.x

12. Carlberg C. Vitamin D genomics: from in vitro to in vivo. Front Endocrinol. (2018) 9:250. doi: 10.3389/fendo.2018.00250

13. Boonstra A, Barrat FJ, Crain C, Heath VL, Savelkoul HF, O'Garra A. 1alpha,25-Dihydroxyvitamin $\mathrm{d} 3$ has a direct effect on naive CD4(+) T cells to enhance the development of Th2 cells. J Immunol. (2001) 167:497480. doi: 10.4049/jimmunol.167.9.4974

14. Zhang Y, Leung DY, Richers BN, Liu Y, Remigio LK, Riches DW, et al. Vitamin D inhibits monocyte/macrophage proinflammatory cytokine production by targeting MAPK phosphatase-1. J Immunol. (2012) 188:212735. doi: 10.4049/jimmunol.1102412

15. Greiller CL, Martineau AR. Modulation of the immune response to respiratory viruses by vitamin D. Nutrients. (2015) 7:424070. doi: $10.3390 /$ nu7064240

\section{AUTHOR CONTRIBUTIONS}

GF and CB had the conception, designed the work, and collected the data. GF, CB, and LS contributed to the data analysis, its interpretation and to the article's writing and editing. $\mathrm{AB}$ and $\mathrm{MZ}$ made the critical revision of the article. All authors contributed to the article and approved the submitted version.

\section{FUNDING}

This work was supported by the PhD grant 2461/26/17.01.2020 University of Medicine and Pharmacy, Iuliu Hatieganu, Cluj-Napoca, Romania.

16. Douros K, Boutopoulou B, Fouzas S, Loukou I. Asthma and allergy "epidemic" and the role of vitamin D deficiency. Adv Exp Med Biol. (2017) 996:16983. doi: 10.1007/978-3-319-56017-5_14

17. Hypponen E, Berry DJ, Wjst M, Power C. Serum 25-hydroxyvitamin D and IgE - a significant but nonlinear relationship. Allergy. (2009) 64:61320. doi: 10.1111/j.1398-9995.2008.01865.x

18. Telcian AG, Zdrenghea MT, Edwards MR, Laza-Stanca V, Mallia P, Johnston SL, et al. Vitamin D increases the antiviral activity of bronchial epithelial cells in vitro. Antiviral Res. (2017) 137:93-101. doi: 10.1016/j.antiviral.2016.11.004

19. Song Y, Qi H, Wu C. Effect of 1,25-(OH)2D3 (a vitamin D analogue) on passively sensitized human airway smooth muscle cells. Respirology. (2007) 12:486-94. doi: 10.1111/j.1440-1843.2007.01099.x

20. Wang Z, Zhang H, Sun X, Ren L. The protective role of vitamin D3 in a murine model of asthma via the suppression of TGF-beta/Smad signaling and activation of the Nrf2/HO-1 pathway. Mol Med Rep. (2016) 14:238996. doi: 10.3892/mmr.2016.5563

21. Hossein-nezhad A, Holick MF. Vitamin D for health: a global perspective. Mayo Clin Proc. (2013) 88:720-55. doi: 10.1016/j.mayocp.2013.05.011

22. Mirzakhani H, Al-Garawi A, Weiss ST, Litonjua AA. Vitamin D and the development of allergic disease: how important is it? Clin Exp Allergy. (2015) 45:114-25. doi: 10.1111/cea.12430

23. Holick MF, Chen TC. Vitamin D deficiency: a worldwide problem with health consequences. Am J Clin Nutr. (2008) 87:1080S-6S. doi: 10.1093/ajcn/87.4.1080S

24. Sacheck JM, Van Rompay MI, Chomitz VR, Economos CD, Eliasziw M, Goodman E, et al. Impact of three doses of vitamin D3 on serum 25(OH)D deficiency and insufficiency in at-risk schoolchildren. J Clin Endocrinol Metab. (2017) 102:4496-505. doi: 10.1210/jc.2017-01179

25. Grossman Z, Hadjipanayis A, Stiris T, Del Torso S, Mercier JC, Valiulis A, et al. Vitamin D in European children-statement from the European Academy of Paediatrics (EAP). Eur J Pediatr. (2017) 176:82931. doi: 10.1007/s00431-017-2903-2

26. Holick MF, Binkley NC, Bischoff-Ferrari HA, Gordon CM, Hanley DA, Heaney RP, et al. Evaluation, treatment, and prevention of vitamin D deficiency: an endocrine society clinical practice guideline. J Clin Endocrinol Metab. (2011) 96:1911-30. doi: 10.1210/jc.2011-0385

27. DelGiudice NJ, Street N, Torchia RJ, Sawyer SS, Bernard SA, Holick MF. Vitamin D prescribing practices in primary care pediatrics: underpinnings from the health belief model and use of web-based delphi technique for instrument validity. J Pediatr Health Care. (2018) 32:536-47. doi: 10.1016/j.pedhc.2018.03.003

28. Litonjua AA, Carey VJ, Laranjo N, Harshfield BJ, McElrath TF, O'Connor GT, et al. Effect of prenatal supplementation with vitamin D on asthma or recurrent wheezing in offspring by age 3 years: the vdaart randomized clinical trial. JAMA. (2016) 315:362-70. doi: 10.1001/jama.2015.18589

29. Braegger C, Campoy C, Colomb V, Decsi T, Domellof M, Fewtrell M, et al. Vitamin D in the healthy European paediatric population. J Pediatr Gastroenterol Nutr. (2013) 56:692-701. doi: 10.1097/MPG.0b013e31828f3c05 
30. Gupta A, Bush A, Hawrylowicz C, Saglani S. Vitamin D and asthma in children. Paediatr Respir Rev. (2012) 13:23643. doi: 10.1016/j.prrv.2011.07.003

31. Rusinska A, Pludowski P, Walczak M, Borszewska-Kornacka MK, Bossowski A, Chlebna-Sokol D, et al. Vitamin D Supplementation guidelines for general population and groups at risk of vitamin d deficiency in polandrecommendations of the polish society of pediatric endocrinology and diabetes and the expert panel with participation of national specialist consultants and representatives of scientific societies-2018 update. Front Endocrinol. (2018) 9:246. doi: 10.3389/fendo.2018.00246

32. Uysalol M, Uysalol EP, Yilmaz Y, Parlakgul G, Ozden TA, Ertem HV, et al. Serum level of vitamin D and trace elements in children with recurrent wheezing: a cross-sectional study. BMC Pediatr. (2014) 14:270. doi: 10.1186/1471-2431-14-270

33. Eroglu C, Demir F, Erge D, Uysal P, Kirdar S, Yilmaz M, et al. The relation between serum vitamin D levels, viral infections and severity of attacks in children with recurrent wheezing. Allergol Immunopathol. (2019) 47:5917. doi: 10.1016/j.aller.2019.05.002

34. Dogru M, Seren LP. Serum 25-hydroxyvitamin D levels in children with recurrent wheezing and relation to the phenotypes and frequency of wheezing. Eur Ann Allergy Clin Immunol. (2017) 49:257-62. doi: 10.23822/EurAnnACI.1764-1489.14

35. Pecanha MB, Freitas RB, Moreira TR, Silva LS, Oliveira LL, Cardoso SA. Prevalence of vitamin D deficiency and its relationship with factors associated with recurrent wheezing. J Bras Pneumol. (2019) 45:e20170431. doi: 10.1590/1806-3713/e20170431

36. McNally JD, Leis K, Matheson LA, Karuananyake C, Sankaran K, Rosenberg AM. Vitamin D deficiency in young children with severe acute lower respiratory infection. Pediatr Pulmonol. (2009) 44:9818. doi: 10.1002/ppul.21089

37. Vo P, Koppel C, Espinola JA, Mansbach JM, Celedon JC, Hasegawa K, et al. Vitamin D Status at the time of hospitalization for bronchiolitis and its association with disease severity. J Pediatr. (2018) 203:41622.e1. doi: 10.1016/j.jpeds.2018.07.097

38. Roth DE, Jones AB, Prosser C, Robinson JL, Vohra S. Vitamin D status is not associated with the risk of hospitalization for acute bronchiolitis in early childhood. Eur J Clin Nutr. (2009) 63:297-9. doi: 10.1038/sj.ejcn.1602946

39. Jat KR. Vitamin D deficiency and lower respiratory tract infections in children: a systematic review and meta-analysis of observational studies. Trop Doct. (2017) 47:77-84. doi: 10.1177/0049475516644141

40. Wei Z, Zhang J, Yu X. Maternal vitamin D status and childhood asthma, wheeze, and eczema: A systematic review and meta-analysis. Pediatr Allergy Immunol. (2016) 27:612-9. doi: 10.1111/pai.12593

41. Christensen N, Sondergaard J, Fisker N, Christesen HT. Infant respiratory tract infections or wheeze and maternal vitamin D in pregnancy: a systematic review. Pediatr Infect Dis J. (2017) 36:384-91. doi: 10.1097/INF.0000000000001452

42. Pacheco-Gonzalez RM, Garcia-Marcos L, Morales E. Prenatal vitamin D status and respiratory and allergic outcomes in childhood: a metaanalysis of observational studies. Pediatr Allergy Immunol. (2018) 29:24353. doi: $10.1111 /$ pai.12876

43. Feng $\mathrm{H}$, Xun P, Pike K, Wills AK, Chawes BL, Bisgaard $\mathrm{H}$, et al. In utero exposure to 25-hydroxyvitamin $\mathrm{D}$ and risk of childhood asthma, wheeze, and respiratory tract infections: a meta-analysis of birth cohort studies. J Allergy Clin Immunol. (2017) 139:1508-17. doi: 10.1016/j.jaci.2016. 06.065

44. Litonjua AA, Carey VJ, Laranjo N, Stubbs BJ, Mirzakhani H, O'Connor GT, et al. Six-year follow-up of a trial of antenatal vitamin D for asthma reduction. N Engl J Med. (2020) 382:525-33. doi: 10.1056/NEJMoa19 06137

45. Aglipay M, Birken CS, Parkin PC, Loeb MB, Thorpe K, Chen Y, et al. Effect of high-dose vs standard-dose wintertime vitamin d supplementation on viral upper respiratory tract infections in young healthy children. JAMA. (2017) 318:245-54. doi: 10.1001/jama.2017.8708

46. Hueniken K, Aglipay M, Birken CS, Parkin PC, Loeb MB, Thorpe KE, et al. Effect of high-dose vitamin D supplementation on upper respiratory tract infection symptom severity in healthy children. Pediatr Infect Dis J. (2019) 38:564-8. doi: 10.1097/INF.0000000000002225

47. Aglipay M, Maguire JL. Vitamin D supplementation and upper respiratory tract infections in children-reply. JAMA. (2017) 318:2139-40. doi: 10.1001/jama.2017.15154

48. Martineau AR, Jolliffe DA, Hooper RL, Greenberg L, Aloia JF, Bergman P, et al. Vitamin D supplementation to prevent acute respiratory tract infections: systematic review and meta-analysis of individual participant data. BMJ. (2017) 356:i6583. doi: 10.1136/bmj.i6583

49. Hibbs AM, Ross K, Kerns LA, Wagner C, Fuloria M, Groh-Wargo S, et al. Effect of vitamin D supplementation on recurrent wheezing in black infants who were born preterm: the $\mathrm{D}$-wheeze randomized clinical trial. JAMA. (2018) 319:2086-94. doi: 10.1001/jama.2018.5729

50. Loeb M, Dang AD, Thiem VD, Thanabalan V, Wang B, Nguyen NB, et al. Effect of vitamin D supplementation to reduce respiratory infections in children and adolescents in Vietnam: a randomized controlled trial. Influenza Other Respir Viruses. (2019) 13:176-83. doi: 10.1111/irv.12615

51. Hong M, Xiong T, Huang J, Wu Y, Lin L, Zhang Z, et al. Association of vitamin D supplementation with respiratory tract infection in infants. Matern Child Nutr. (2020) 2020:e12987. doi: 10.1111/mcn.12987

52. Das RR, Singh M, Naik SS. Vitamin D as an adjunct to antibiotics for the treatment of acute childhood pneumonia. Cochrane Database Syst Rev. (2018) 7:Cd011597. doi: 10.1002/14651858.CD011597.pub2

53. Cassim R, Russell MA, Lodge CJ, Lowe AJ, Koplin JJ, Dharmage SC. The role of circulating 25 hydroxyvitamin D in asthma: a systematic review. Allergy. (2015) 70:339-54. doi: 10.1111/all.12583

54. Urashima M, Segawa T, Okazaki M, Kurihara M, Wada Y, Ida H. Randomized trial of vitamin D supplementation to prevent seasonal influenza A in schoolchildren. Am J Clin Nutr. (2010) 91:1255-60. doi: 10.3945/ajcn.2009.29094.

Conflict of Interest: The authors declare that the research was conducted in the absence of any commercial or financial relationships that could be construed as a potential conflict of interest.

Copyright (c) 2020 Feketea, Bocsan, Stanciu, Buzoianu and Zdrenghea. This is an open-access article distributed under the terms of the Creative Commons Attribution License (CC BY). The use, distribution or reproduction in other forums is permitted, provided the original author(s) and the copyright owner(s) are credited and that the original publication in this journal is cited, in accordance with accepted academic practice. No use, distribution or reproduction is permitted which does not comply with these terms. 